SIR,

\section{Whirled patterns in thawing snow}

Figure 1 shows unexplained patterns in snow which were observed in spring 1975 in the Munzur mountains of central Turkey at about $2000 \mathrm{~m}$ a.s.l. They occurred near the foot of a north-facing slope, at or near the edge of a rapidly thawing winter snow mass.

The patterns consisted of a series of whirls, each up to 6$8 \mathrm{~m}$ in diameter, with a central "navel" (up to $1 \mathrm{~m}$ across) from which a regular series of curved radial furrows arced in an anticlockwise direction. The snow in the furrows was 10-15 cm deep, and had a somewhat dirty, "used" look.
This photograph (and others) has been shown to many earth scientists, glaciologists and geographers in Europe, the Middle East and North America, but no reasonable suggestion as to how these patterns could have formed has yet been made. Have any of your readers observed similar phenomena, and can they offer any suggestions for their origin?

101A New Road,

ALAN WELLS

Haslingfield,

Cambridge CB3 $7 L P$,

England

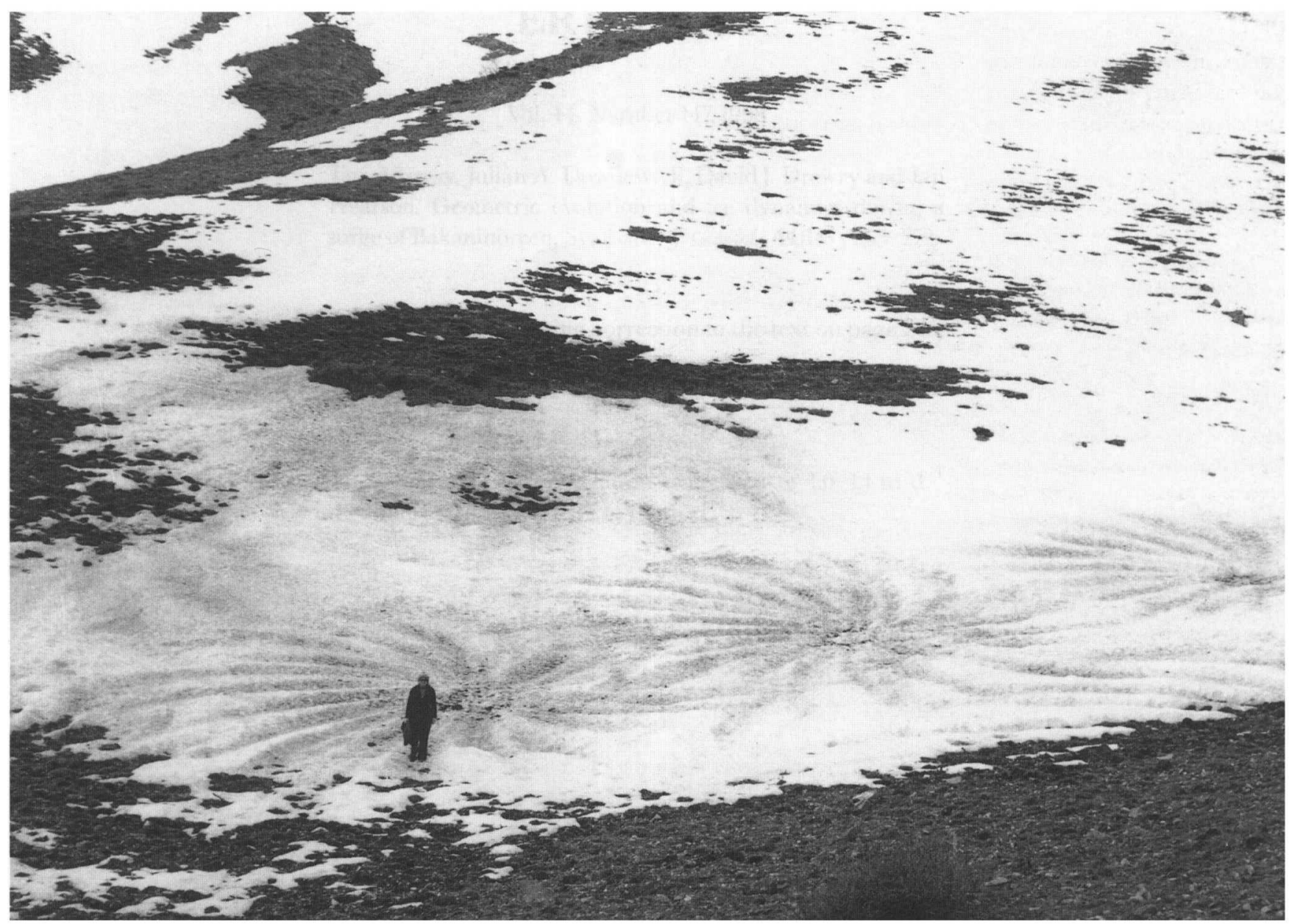

Fig. 1. Enigmatic whirled patterns in spring-thaw snow in remote mountains of central Turkey (adult in foreground is $1.7 \mathrm{~m}$ ). 